\title{
Ebola epidemic outpacing response: MSF
}

$\mathrm{M}$ ore international action is needed to quell the West Africa Ebola epidemic, says Dr. Joanne Liu, international president of medical relief organization Médecins Sans Frontières (MSF). "The situation is deteriorating faster than the response is being brought."

Recently, the World Health Organization (WHO) declared the outbreak a public health emergency of international concern and the United Nations Secretary General appointed a special envoy to coordinate global efforts to fight the disease.

But without immediate, practical action and more boots on the ground it won't be possible to turn the tide, says Liu, a Montréal physician. "We need more people to do the legwork in terms of health promotion, surveillance, data collection, tracing people who have had contact with the infected, and ensuring funerals are done in safe ways, but it's not happening."

Ebola outbreaks in Guinea, Liberia, Sierra Leone and Nigeria continue unabated. WHO confirmed Aug. 27 that the epidemic has also spread to the Democratic Republic of the Congo. As of Aug. 22, nearly 1500 people have died.

Families are being wiped out, health services are overrun, and MSF is at the limit of its capacity to help, says Liu.

She joined CMAJ by telephone to share what she witnessed on a recent trip to Guinea, Liberia and Sierra Leone.

CMAJ: What's the status of the epidemic and response from what you saw?

Liu: Guinea has been dealing with the outbreak since March and ... their main challenge is to remain vigilant despite the fact that the numbers are stabilizing. For Sierra Leone and Liberia, we are still somehow in the upward swing, particularly in Liberia. ... We recently opened a big centre in Monrovia with 120 beds [four times the size

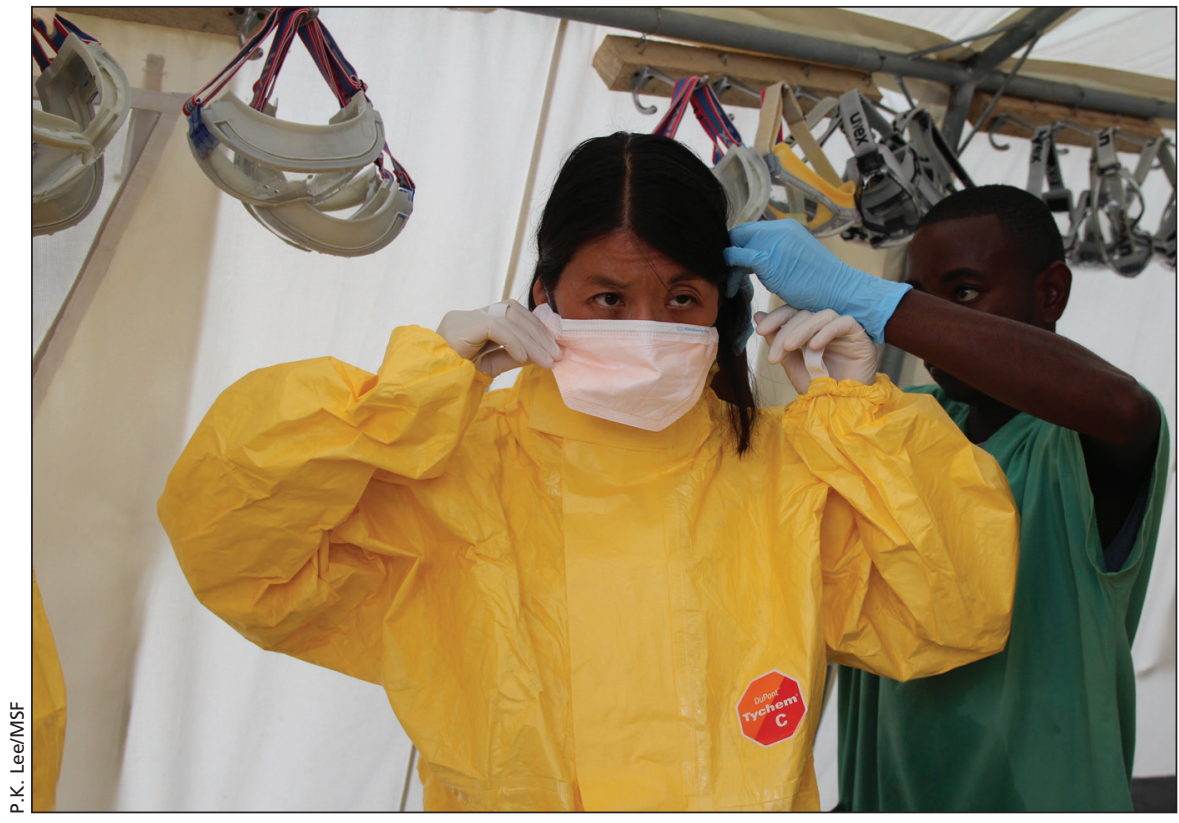

The West Africa Ebola epidemic will not be contained without a massive deployment on the ground, says Médecins Sans Frontières International President Dr. Joanne Liu.

of any other Ebola centre] and already it's overcrowded.

CMAJ: Why has this outbreak been so much larger and more deadly than any on record?

Liu: In the past, the outbreaks happened in isolated villages and the chain of transmission stopped fairly quickly. ... Now it has hit big cities. ... There are more people who are exposed [to the virus].

CMAJ: Do you share WHO's concerns that the current epidemic may be bigger and more serious than reports indicate?

Liu: We know that the capacity for data collection is suboptimal. We often hear about deaths in the community, but we cannot go and verify [those reports] so we have a strong feeling [that the true scale] is underestimated.

CMAJ: What are the upshots of the current human resources shortages in the field?

Liu: Everyone thinks that the only way to do something for Ebola right now is to come in with a space suit and work in isolation wards, but [the biggest shortages are in nonclinical roles]. ... In Kailahun [in Sierra Leone] we know there are 2000 people who have been in contact with our patients, but we're only able to follow up with 250 of them. That doesn't require special equipment or training, but it's not happening because we don't have the manpower.

CMAJ: Does MSF plan to scale up efforts in the region to meet these shortages?

Liu: There are so many other crises in the world right now - in South Sudan, the Central African Republic, Syria, Gaza and Iraq - it's not possible for us to scale up more. ... The response and solution won't come from one organization. State governments from rich countries, plus the UN agencies, need to step up to the plate.

CMAJ: What do you think about Canada's contribution of 1000 doses of an experimental drug to fight the disease? 
Liu: It's good because it's going to be a catalyst in terms of moving forward research and development. But we need to be realistic. For this epidemic, it's very unlikely the use of those few doses will make a difference.

CMAJ: What immediate next steps would you like to see in an international response?

Liu: We need to restore basic health care access. ... Right now in Liberia, there's no place to consult for general medical problems. In Monrovia, all the hospitals are closed. ... This week, six pregnant women walked around the city for hours to find a place to deliver and ended up at our Ebola centre, which was not the right place to be, and by the time they got there, had lost their pregnancies.
CMAJ: Are there other pressing social consequences that are overlooked in current efforts?

Liu: What's most distressing is the fact that [patients with Ebola] face a solitary death, without their loved ones, surrounded by people wearing space suits. ... This is why people are so scared, why they don't come to hospitals, and why there's such an issue about safe burial.

CMAJ: Health personnel in the field have reported unsafe working conditions, for example, not enough gloves to go around - is this something you heard about on your visit?

Liu: This has been brought to our attention. People were not completely aware of what was going on at first, so health care personnel didn't take the precautions to protect themselves.
CMAJ: Are you concerned for the safety of your own personnel?

Liu: I can't deny we have concern, especially as our facilities are so overcrowded, and that's why we're asking more players to come to the field and take some responsibility.

CMAJ: Is international "Ebola hysteria" making it more difficult to curb the epidemic?

Liu: Having fewer airlines coming in is an issue. Of course I understand why people are doing that, but I don't think it's helpful. The best way to contain the epidemic today is to increase the means to respond to it locally, not closing borders and barricading ourselves. - Lauren Vogel, CMAJ

CMAJ 2014. DOI:10.1503/cmaj.109-4890 